\title{
Efficiency Examination of The Circular Coils with Two Types of Cross-Sections for WPT System
}

\author{
Zakarya A. Atraqchi', Yasir M.Y. Ameen ${ }^{2}$, Ahmad T. Younis ${ }^{3}$ \\ zakarya.atraqchi@gmail.com ${ }^{1}$, yasir_752000@yahoo.com ${ }^{2}, \underline{\text { ahmedyounis1959@gmail.com }^{3}}$ \\ ${ }^{1,3}$ Department of Electronic Engineering, Collage of Electronic Engineering, University \\ of Ninevah, ${ }^{2}$ Department of Electrical Engineering, University of Mosul
}

\begin{abstract}
In recent years, research on resonant inductive coupling wireless power transmission (WPT) systems has been dominant for use in wireless chargers due to their flexibility and particular use compared to conventional cable charging systems. This paper presents a simulation study of the effect of changing the copper wire cross-section i.e. circular and rectangular cross-section wire on the coil's parameters. Two types of compensation topologies SS (series-series ) and SP (seriesparallel) are used for symmetrical and unsymmetrical coils The theoretical analysis and modeling of both compensation topologies were carried out and each time the impact on the efficiency of energy transmission was determined. The result shows that the SP topology offers better efficiency than the SS when Tx and Rx are asymmetrical.
\end{abstract}

Keywords: WPT, IPT, WPT Coils, Circular Coils, Circular Cross Section Wire, Rectangular Cross Section Wire, SS Compensation Topologies, SP Compensation Topologies.

\section{Introduction}

Resonant inductive coupling wireless power transfer (WPT) has become one of the most requested technologies in recent years, such as in biomedical equipment, mobile phone charger, and electric-car. Nikola Tesla first presented the idea of WPT In the late 19th century[1]. WPT systems can be used as a workaround to eliminate certain cable-related charging risks and provide the power required by on-demand charging devices, making them more flexible and energy-efficient, it also helps to make the contact-free devices waterproof and dustproof [2]. WPT can be classified into two classes Far filed (radiative) WPT and Near filed (non-radiative) WPT [3].

Far-field technologies use electromagnetic waves propagating power as same in radio transmit signals. This technique was used to control radio frequency identification (RFID) using ultra-high frequency (UHF) detection without the need to use batteries and with a wide operations range [4]. The tradeoff between directionality and transmission efficiency is one of the disadvantages of the far-field system. Using high-gain antennas various microwave RF devices transferring power with an efficiency of $90 \%$ over kilometers distance [5],[6].

In 2007, the Massachusetts Institute of Technology (MIT) Researchers, proposed a nonradiative WPT technique that uses magnetic resonance coupling (MRC) [7]. They have been using four of $30 \mathrm{~cm}$ diameter self-resonant coils to the light of 60 -watt bulb at a range of $2 \mathrm{~m}$ and output efficiency of $40 \%$ [7]. In 2010 the A. P. Sample presents a WPT system with $70 \%$ efficiency for a distance range of $0-70 \mathrm{~cm}$ that has a receiver coil with fixed-load that moving to almost any position within the transmitter range [8].

The near-field WPT transfer the energy from the transmitter coil to the receiver coil and its operation based on the resonant magnetic coupling. Typically, the resonant frequency of the 
coils is calculated from the self-inductance of the coils with a capacitor that added to the circuit to works as compensation elements.[9],[10]. Inductive resonant WPT technology can be a good way to charge mobile phones, robot, implantable medical devices, etc. Nonetheless, inductive resonant WPT gives advantages compared with other technologies at the short and medium distance range, but this technique remains restricted as a result of changing in resonance frequency with any changing in distance between the transmitter (Tx) coil and the receiver (Rx) coil that effects on the efficiency [11],[12]. Several studies were carried out to improve efficiency. The WPT circuit model and resonant frequency analysis were achieved in [13]. A technique for maximizing the efficiency of the WPT method using SS topology is proposed in[14]. Series and parallel compensation topology analysis for inductive WPT was carried out to achieve optimal efficiency and load voltage achieved in [15]. WPT with hybrid compensation topologies that give constant output voltage and current to use for charging batteries are discussed in [16]. An overall theory on SP-combined topology and equations of efficiency has been studied in [17]. The analyses of WPT with Series-Series (SS) and Series-parallel (SP)compensation topology are provided in[18].

The coil shape is impacting on the efficiency and it is a very important parameter on the design, also has an effect on the distance of the power transformation of the WPT system, so different shapes of the coils can be selected for various applications such as circular helix coils that used in [19],[20], whereas in [21],[22] planar spiral coils were used, while in [23],[24] the coils used have a square helix shape.

This paper study the effect of changing the Copper wire cross-section on the coil's parameter and design symmetrical and asymmetrical coils and also study the effect of the compensation topologies on the efficiency of the power transmission.

\section{Theoretical Background of Resonant Inductive Coupling WPT}

A resonant inductive coupling WPT consists of two-stage that operating in the same resonant frequency to allowing high-efficiency power transmission [7]. A typical RLC circuit can be used to model this system, as illustrated in Figure 1. The Tx coil that connected in the source side is magnetically coupled with the Rx coil that connected to the load side. the power transmission efficiency of the system is determined by two factors:

1) The resonators quality factor $(Q)$ which is defined by[25]:

$$
\mathrm{Q}=\frac{1}{\mathrm{R}} \sqrt{\frac{\mathrm{L}}{\mathrm{C}}}=\frac{\omega_{0} \mathrm{~L}}{\mathrm{R}}
$$

Where: $\omega_{0}=\frac{1}{\sqrt{L C}}$ indicates the resonant frequency,

$\mathrm{L}$ : indicates to the self-inductance of the primary $\mathrm{L}_{1}$ or $\mathrm{L}_{2}$ for the secondary stage.

$\mathrm{C}$ : indicates to the compensation capacitor of the primary $\mathrm{C}_{1}$ or $\mathrm{C}_{2}$ for the secondary stage.

$\mathrm{R}$ : indicates to the equivalent resistance of the primary side $\mathrm{R}_{1}$ or $\mathrm{R}_{2}$ for the secondary side As the $\mathrm{Q}$ factor increases the power transformation increase and power loss decrease [25].

2) The mutual inductance between the Tx and Rx coils (M) which is defined by[25], [7]:

$$
\mathbf{M}=\mathbf{k} \sqrt{\mathbf{L}_{1} * \mathbf{L}_{2}} .
$$


Where $\mathbf{k}$ is the coupling coefficient between the Tx and Rx coils identified by the distance between the coils. Which is defined by equation (3) below for circle coils[25]:

$$
k=\frac{1}{\left[1+2^{\frac{2}{3}}\left(\frac{h}{\sqrt{r_{1} * \mathbf{r}_{2}}}\right)^{2}\right]^{\frac{3}{2}}}
$$

Where: $\mathrm{h}$ is the air gap (distance) between the two coils Tx and Rx of the WPT, Rx.

$r_{1}$ and $r_{2}$ are the radii of the Tx and the Rx coils respectively.

The resonant inductive coupling WPT approach can be transfer power to a distance longer than the inductive coupling WPT approach (without resonant) because of the compensation element in the magnetic resonant coupling circuit, it has almost no harm to humans because it is non-radiative and it doesn't need line of sight path [26]. One of the resonant inductive coupling WPT approach disadvantages is susceptible to misalignment, also other disadvantages, when it used for charging multiple devices the resonant frequency is difficult to adjust [27].

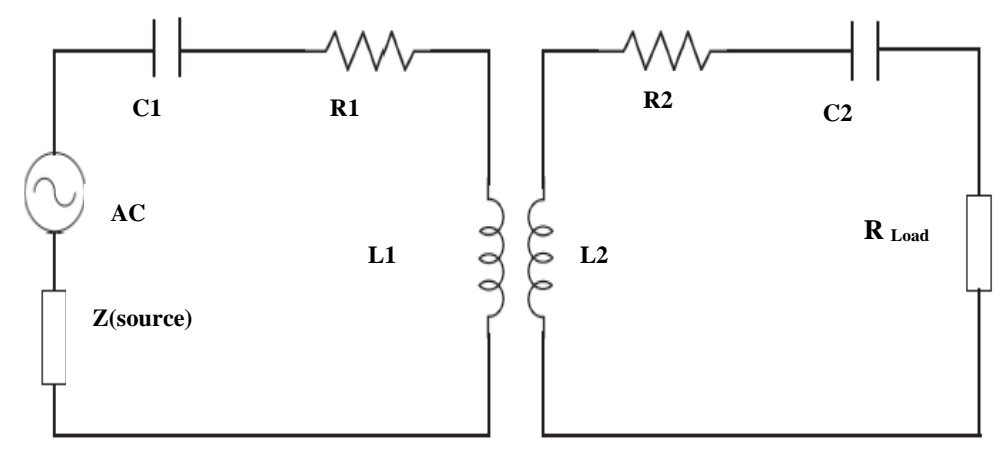

Fig.1 equivalent circuit of resonant inductive coupling WPT.

Two compensation topologies are used in this paper SS and SP as shown in Figure 2. The equations of efficiency of the SS circuit is derived using Kirchhoff's voltage law (KVL) [28]:

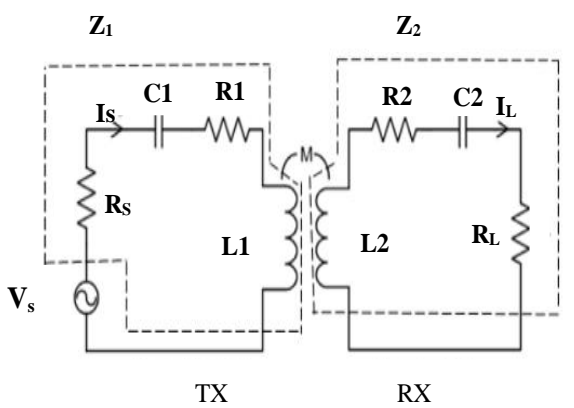

(a)

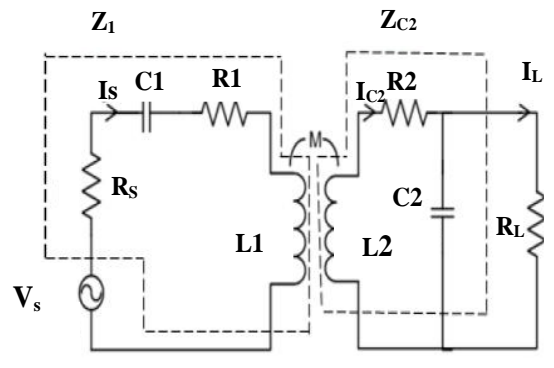

TX
$\mathrm{RX}$

(b)

Fig.2 (a) WPT with SS compensation topologies (b) WPT with SP compensation topologies 


$$
\eta_{s s}=\frac{p_{\text {out }_{S S}}}{\mathrm{p}_{\text {in }_{\mathrm{SS}}}} * 100=\frac{\mathrm{I}_{\mathrm{L}}{ }^{2} \mathrm{R}_{\mathrm{L}}}{\mathrm{v}_{\mathrm{S}} \mathrm{I}_{\mathrm{S}}}
$$

Where:

$$
\mathrm{I}_{\mathrm{s}}=\frac{\mathrm{Z}_{2} \mathrm{~V}_{\mathrm{S}}}{\mathrm{Z}_{1} \mathrm{Z}_{2}+(\omega \mathrm{M})^{2}}
$$

And:

$$
I_{L}=\frac{j w M v_{S}}{z_{1} Z_{2}+(\omega M)^{2}}
$$

Also, the efficiency of the SP compensation topologies circuit is derived in [28]:

$$
\mathrm{\eta}_{s p}=\frac{p_{\text {out }} \text { sp }}{p_{\text {in }} p} * 100=\frac{I_{L}{ }^{2} R_{L}}{V_{S} I_{S}}
$$

The Cramer's rule was used in calculating the currents $\mathrm{I}_{\mathrm{S}}$ and $\mathrm{I}_{\mathrm{L}}$ :

$$
A=\left[\begin{array}{ccc}
Z_{1} & -j \omega M & 0 \\
-j \omega M & Z_{C 2} & -\frac{1}{j \omega C_{2}} \\
0 & -\frac{1}{j \omega C_{2}} & \frac{1}{j \omega C_{2}}+R_{L}
\end{array}\right]
$$

Where:

$$
I_{S}=\frac{V_{s}}{A}\left[Z_{C 2}\left(\frac{1}{j \omega C_{2}}+R_{L}\right)+\frac{1}{\omega^{2} C_{2}^{2}}\right]
$$

And:

$$
\mathrm{I}_{\mathrm{L}}=\frac{\mathrm{V}_{\mathrm{s}}}{\mathrm{A}}\left(\frac{\mathrm{M}}{\mathrm{C}_{2}}\right)
$$

\section{Design and Simulation of Symmetrical and Asymmetrical Circular Coils}

The most common coil structure in the WPT system is spiral design because the electromagnetic field characteristics are very limited and compact size. A research was carried out on many coils with structure circular helix, square helix, planar spiral[29]. The previous study has shown that the coils with a circular helix structure give the highest efficiency, also under optimal load, it gives the largest air gap as compared with the other structures, while the 
planar spiral structure gives the bad efficiency as compared with the other coils structures. In the WPT system. The optimal load is the load value to achieve maximum efficiency. Another research was conducted on the shape of the coil [30]. It was found that Circular geometries have been found to offer better coupling between the Tx and Rx coils when alignment is perfect between it, while the square coil structure is better if the Tx and Rx coils are not perfectly aligned.

The circular coils structure is chosen for this research because of the above-described advantages. By using the MAXWELL software four different coils are designed by using two types of wire cross-section as shown in Figure 3. In the first and second cases, similar size coils are designed one by using circular cross-section wire and the other case by using rectangular cross-section wire as shown in Figure 4. (a)\&(b), while in the $3^{\text {rd }}$ and $4^{\text {th }}$ cases the Tx coil has been kept in the same size while the receiver coil has been minimized, also by using circular and rectangular cross-section wire as shown in Fig.4 (c) \& (d)

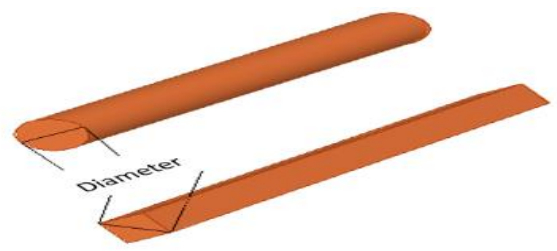

Fig.3 wire cross-section

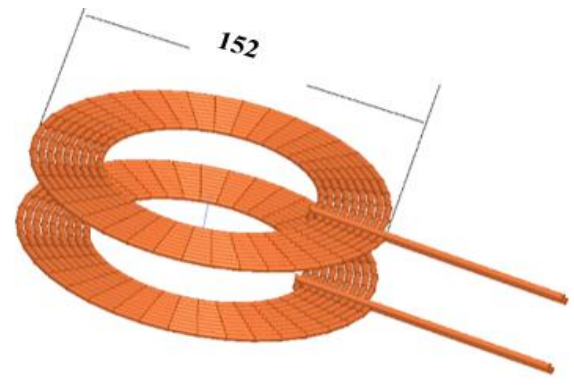

(a)

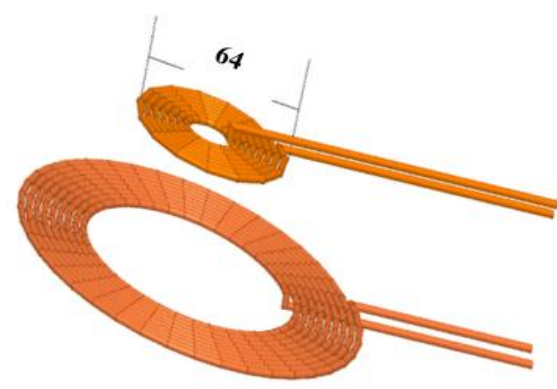

(c)

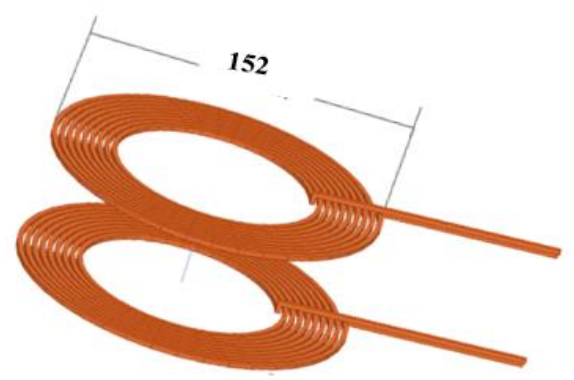

(b)

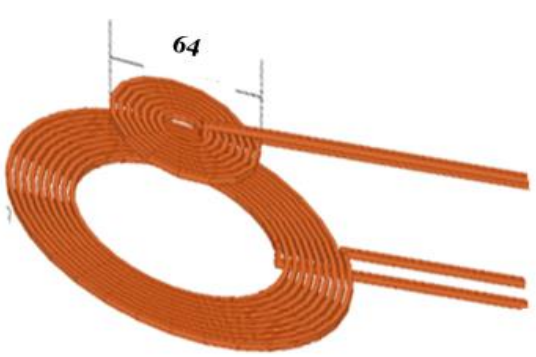

(d)

Fig. 4 (a) Symmetric coils with circular cross-section wire, (b) Symmetric coils with rectangular crosssection-wire, (c) Asymmetric coils with circular cross-section-wire, (d) Asymmetric coils with rectangular cross-section-wire. 
The asymmetric coils designed can be suitable for use in biomedical devices [28]. The parameter's value for the designed coils is given in Table $\mathbf{1}$.

Table.1 parameter's value for the designed coils

\begin{tabular}{ccccc}
\hline & \multicolumn{2}{c}{ Symmetric } & \multicolumn{2}{c}{ Asymmetric } \\
& Tx Coil & Rx Coil & Tx Coil & Rx Coil \\
\hline Polygon Radius $(\mathrm{mm})$ & 1.5 & 1.5 & 1.5 & 1.5 \\
Start Helix Radius $(\mathrm{mm})$ & 45.5 & 45.5 & 45.5 & 9.1 \\
Radius Change $(\mathrm{mm})$ & 3.5 & 3.5 & 3.5 & 3.2 \\
No. of Turns & 9 & 9 & 9 & 7 \\
\hline
\end{tabular}

The MAXWELL software can be used to analyze and simulate the coils designed above using the finite element method (FEM) via using the magnetic solver with excitation current of (1ampere). For Tx and Rx coils, the value of the self-inductance and the coupling coefficients between them are obtained for four different air gaps as shown in Table 2 and Table 3.Figure 5 shows the magnetic field distribution of both coils pairs.

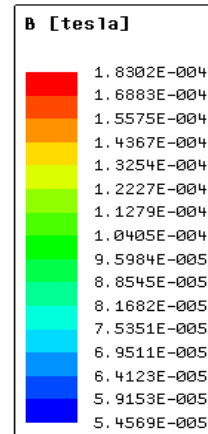

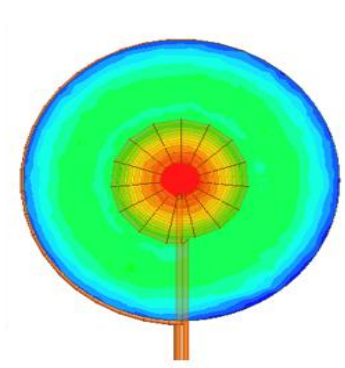

(a)
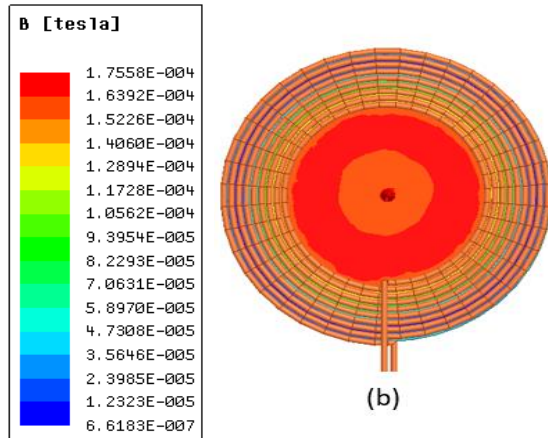

(b)
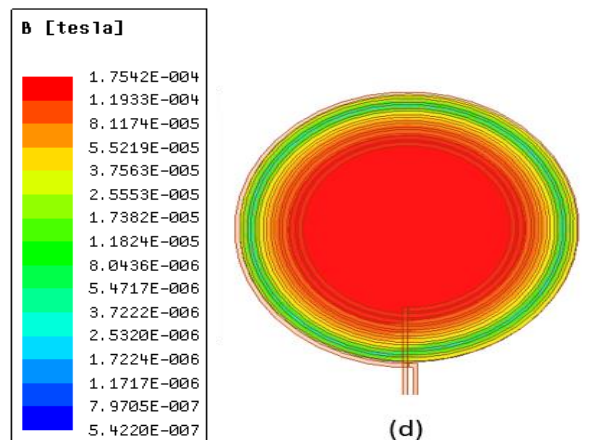

(d)

Fig. 5: (a)Magnetic field distribution of asymmetric coils with circular cross-section wire, (b) Magnetic field distribution of symmetric coils with circular cross-section wire, (c) Magnetic field distribution of asymmetric coils with rectangular cross-section wire, (d) Magnetic field distribution of symmetric coils with rectangular cross-section wire, 
Table.2 Coils simulation result parameter for a circular cross-section

\begin{tabular}{ccccc|cccc}
\hline $\begin{array}{c}\text { Distance } \\
(\mathrm{mm})\end{array}$ & $\mathrm{L}_{\mathrm{Tx}}(\mu \mathrm{H})$ & $\mathrm{L}_{\mathrm{Rx}}(\mu \mathrm{H})$ & $\mathrm{M}(\mu \mathrm{H})$ & $\mathrm{K}$ & $\mathrm{L}_{\mathrm{Tx}}(\mu \mathrm{H})$ & $\mathrm{L}_{\mathrm{Rx}}(\mu \mathrm{H})$ & $\mathrm{M}(\mathrm{nH})$ & $\mathrm{K}$ \\
\hline 30 & 12.9 & 12.9 & 4.1 & 0.32 & 12.9 & 1.9 & 633.4 & 0.126 \\
50 & 12.7 & 12.9 & 2.2 & 0.17 & 12.9 & 1.9 & 360.2 & 0.072 \\
60 & 12.5 & 12.9 & 1.61 & 0.1268 & 12.9 & 1.9 & 264.8 & 0.0351 \\
90 & 10.3 & 12.9 & 0.53 & 0.05 & 12.9 & 1.8 & 88.2 & 0.018 \\
\hline
\end{tabular}

Table.3 Coils simulation result parameter for a rectangular cross-section

\begin{tabular}{ccccc|cccc}
\hline $\begin{array}{c}\text { Distance } \\
(\mathrm{mm})\end{array}$ & \multicolumn{5}{c|}{ Symmetrical } & \multicolumn{4}{c}{ Asymmetrical } \\
& $\mathrm{L}_{\mathrm{Tx}}(\mu \mathrm{H})$ & $\mathrm{LRx}(\mu \mathrm{H})$ & $\mathrm{M}(\mu \mathrm{H})$ & $\mathrm{K}$ & $\mathrm{LTx}(\mu \mathrm{H})$ & $\mathrm{LRx}(\mu \mathrm{H})$ & $\mathrm{M}(\mathrm{nH})$ & $\mathrm{K}$ \\
\hline 30 & 13 & 13 & 4.01 & 0.31 & 12.9 & 1.98 & 527 & 0.12 \\
50 & 12.8 & 13 & 2.2 & 0.16 & 12 & 1.98 & 293 & 0.06 \\
60 & 12.6 & 13 & 1.611 & 0.125 & 11.4 & 1.98 & 175 & 0.04 \\
90 & 10.4 & 13 & 0.53 & 0.05 & 11.4 & 1.98 & 84 & 0.017 \\
\hline
\end{tabular}

Where: $\left(\mathrm{L}_{\mathrm{Tx}}\right)$ is the transmitter coil self-inductance, $\left(\mathrm{L}_{\mathrm{Rx}}\right)$ is the receiver coil self-inductance.

\section{Inductive Coupling WPT Realization}

As shown in Figure 6, the simulation software ANSYS Simplorer is used to simulate a schematic diagram of the SS and SP topology. The designed coils are imported from Maxwell software and putting it in the circuit, the software automatically takes the coils parameter to the circuit.

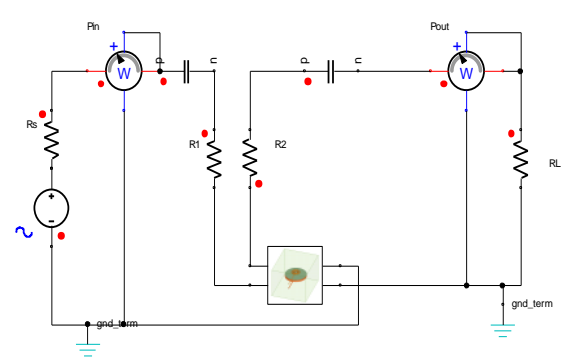

(a)

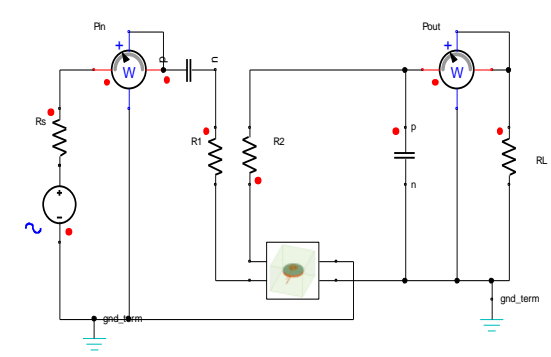

(b)

Fig.6: (a) Simulation circuit of SS topology (b) Simulation circuit of SP topology

The efficiency is calculated at the resonance frequency $\mathrm{f}=100 \mathrm{KHz}$. The results of Tables 2 and 3 with an air gap distance of $30 \mathrm{~mm}$ are used to calculate the capacitance values. In the case of symmetrical structure, the calculated capacitance values for the transmitter side and the receiver side were $\mathrm{C}=0.194 \mu \mathrm{F}$. whereas, $\mathrm{C}=1.333 \mu \mathrm{F}$ for the small coil on the receiver side 
and $\mathrm{C}=0.194$ for the large coil in an asymmetrical design. It is worth noting that the circuit has been supplied with $\mathrm{Vs}_{\mathrm{s}}=12$ and loaded with $\mathrm{RL}=10 \Omega$. The values of $\mathrm{Rdc}$ and $\mathrm{Rac}$ can be calculated and the result shown in Table 4 takes into account the skin effect of the stranded wire standard at $\mathrm{f}=100 \mathrm{kHz}$.

Table.4 DC and Ac Resistance

\begin{tabular}{ccc|cccc}
\hline Cross- & \multicolumn{2}{c|}{ Symmetric } & \multicolumn{4}{c}{ Asymmetric } \\
section wire & $\mathrm{R}_{\mathrm{dc}}(\mathrm{Tx}=\mathrm{Rx})$ & $\mathrm{R}_{\mathrm{ac}}(\mathrm{Tx}=\mathrm{Rx})$ & $\mathrm{R}_{\mathrm{dc} \mathrm{Tx}}(\mathrm{m} \Omega)$ & $\mathrm{R}_{\mathrm{ac} \mathrm{Tx}}(\mathrm{m} \Omega)$ & $\mathrm{R}_{\mathrm{dc} \mathrm{Rx}}(\mathrm{m} \Omega)$ & $\mathrm{R}_{\mathrm{ac} \mathrm{Rx}}(\mathrm{m} \Omega)$ \\
\hline Circular & 8.47 & 32.1 & 8.47 & 32.1 & 2.726 & 10.4 \\
Rectangular & 13.34 & 37 & 13.34 & 37 & 4.212 & 11.8 \\
\hline
\end{tabular}

\section{Simulation Results}

The simulation is performed for previously designed coils using two types of compensation circuits, i.e. SS and SP topologies for four different air gap distances. The efficiency is calculated from the reading of the wattmeter that measured the input and output power. Figure 7 shows the calculated efficiency for coils with circular and rectangular cross-sections with air gap distances of $30 \mathrm{~mm}, 50 \mathrm{~mm}, 60 \mathrm{~mm}$ and $90 \mathrm{~mm}$. For both coils with either a circular or rectangular cross-section, it can be concluded that the use of the SS compensation circuit with symmetrical or asymmetrical design leads to higher efficiency for almost all distances than the use of the SP compensation circuit. For example, for a circular cross-section with the symmetrical design, the efficiencies at $30 \mathrm{~mm}$ of an air gap correspond to $94.2 \%$ and $73 \%$ for SS or SP.

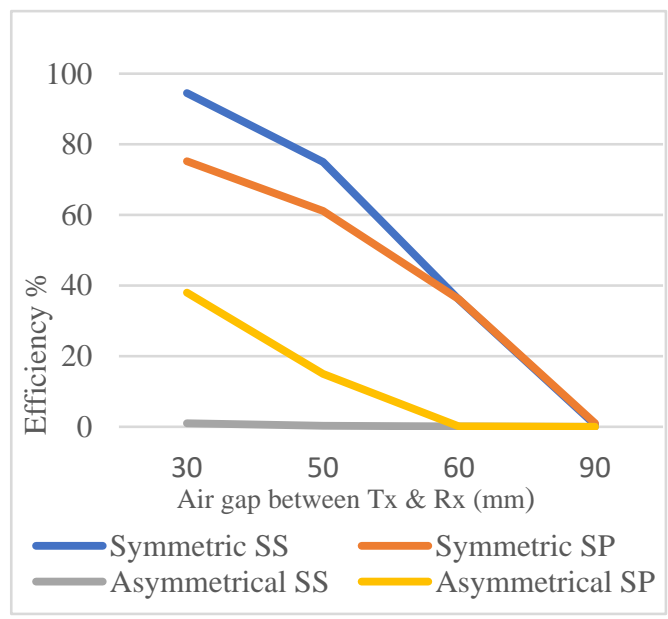

(a)

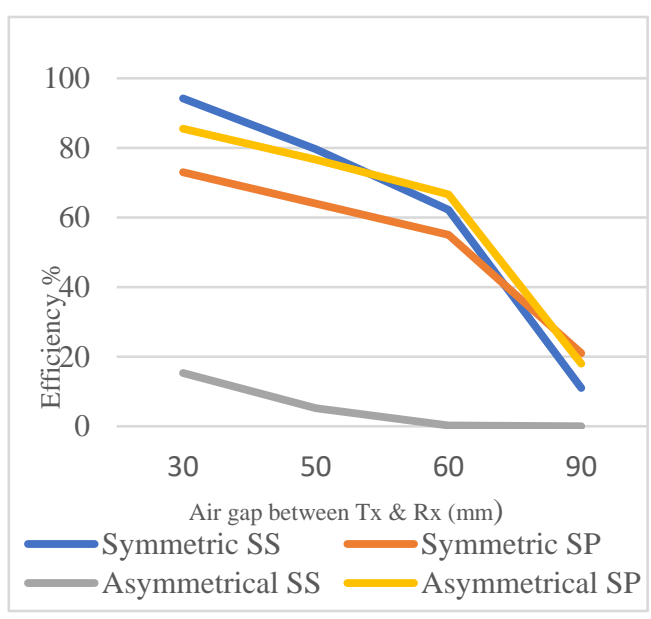

(b)

Fig.7 Chart of efficiency with various topologies and distance of the circular coils (a) Rectangular crosssection wire coils (b) Circular cross-section wire coils 


\section{Conclusion}

A WPT system circuit has been modeling using two types of coils symmetric and asymmetric Each coil was first designed using a circular cross-section wire and then using a rectangular cross-section wire. The efficiency of power transmission for the modeling circuits was examined using SS and SP compensation topologies

The overall results show that the symmetrical coils in, which the Tx and Rx coils are the same sizes, give higher energy transfer efficiency when an SS compensation circuit is used. While the asymmetrical coils, in which the Tx coil is larger than the Rx coil, a higher energy transfer efficiency has been achieved using SP compensation topologies.

It was also found from the results that the symmetrical coils with rectangular cross-section wire are more efficient in transmitting the power over the near distances $(30 \mathrm{~mm})$ than the circular cross-section wire, while the circular cross-section wire is the better in the other distances. In the latter case, the asymmetric coils with a circular cross-section wire gave better efficiency for power transmission over all distances than the rectangular cross-section wire.

\section{References}

[1] N. Tesla, “Apparatus for Transmitting Electrical Energy,” p. 4, 1914.

[2] X. Lu, P. Wang, D. Niyato, D. I. Kim, and Z. Han, "Wireless Charging Technologies: Fundamentals, Standards, and Network Applications," IEEE Commun. Surv. Tutorials, vol. 18, no. 2, pp. 1413-1452, Apr. 2016.

[3] M. S.Y.R. Hui, W.X. Zhong, C.K. Lee, "A Critical Review of Recent Progress in Mid-Range Wireless Power Transfer,” IEEE Trans. Ind. Electron., vol. 61, no. 7, pp. 1-4, 2013.

[4] A. P. Sample, D. J. Yeager, P. S. Powledge, A. V. Mamishev, and J. R. Smith, "Design of an RFID-based battery-free programmable sensing platform," IEEE Trans. Instrum. Meas., vol. 57, no. 11, pp. 2608-2615, 2008.

[5] W. C. Brown, "The History of Power Transmission by Radio Waves," IEEE Trans. Microw. Theory Tech., vol. 32, no. 9, pp. 1230-1242, 1984.

[6] J. O. McSpadden and J. C. Mankins, "Space solar power programs and microwave wireless power transmission technology," IEEE Microw. Mag., vol. 3, no. 4, pp. 46-57, 2002.

[7] Stavros V. Georgakopoulos, "Wireless power transfer in human tissue via Conformal Strongly Coupled Magnetic Resonance," 2015 IEEE Wirel. Power Transf. Conf. WPTC 2015, vol. 61, no. 3, pp. 1378-1384, 2015.

[8] A. P. Sample, D. A. Meyer, and J. R. Smith, "Analysis, experimental results, and range adaptation of magnetically coupled resonators for wireless power transfer," IEEE Trans. Ind. Electron., vol. 58, no. 2, pp. 544-554, 2010.

[9] S. C. Goldstein and B. L. C. Stancil, Daniel D., "Magnetic Resonant Coupling As a Potential Means for Wireless Power Transfer to Multiple Small Receivers," IEEE Trans. Power Electron., vol. 24, no. 7, pp. 1819-1825, 2009.

[10] D. M. Vilathgamuwa and J. P. K. Sampath, "Wireless power transfer (WPT) for electric vehicles (EVs) — present and future trends," Power Syst., vol. 91, pp. 33-60, 2015.

[11] J. Wang, S. L. Ho, W. N. Fu, and M. Sun, "Analytical design study of a novel WiTricity charger with lateral and angular misalignments for efficient wireless energy transmission," IEEE Trans. Magn., vol. 47, no. 10, pp. 2616-2619, 2011.

[12] K. Fotopoulou and B. W. Flynn, "Wireless power transfer in loosely coupled links: Coil misalignment model,” IEEE Trans. Magn., vol. 47, no. 2 PART 2, pp. 416-430, 2011.

[13] Y. Zhang, Z. Zhao, and K. Chen, "Frequency decrease analysis of resonant wireless power transfer," IEEE Trans. Power Electron., vol. 29, no. 3, pp. 1058-1063, 2014.

[14] T. Linlin, Q. Hao, H. Xueliang, C. Weijie, and S. Wenhui, "A Novel Optimization Means of 
Transfer Efficiency for Resonance Coupled Wireless Power Transfer," TELKOMNIKA Indones. J. Electr. Eng., vol. 11, no. 5, 2013.

[15] W. Zhang, S. C. Wong, C. K. Tse, and Q. Chen, "Analysis and comparison of secondary seriesand parallel-compensated inductive power transfer systems operating for optimal efficiency and loadindependent voltage-transfer ratio," IEEE Trans. Power Electron., vol. 29, no. 6, pp. 2979-2990, 2013. [16] X. Qu, H. Han, S. C. Wong, C. K. Tse, and W. Chen, "Hybrid IPT Topologies with Constant Current or Constant Voltage Output for Battery Charging Applications," IEEE Trans. Power Electron., vol. 30, no. 11, pp. 6329-6337, 2015.

[17] S. Liu, L. Chen, Y. Zhou, and T. J. Cui, "A general theory to analyze and design wireless power transfer based on impedance matching," Int. J. Electron., vol. 101, no. 10, pp. 1375-1404, 2014.

[18] M. Rehman, Z. Baharudin, P. Nallagownden, B. U. Islam, and M. Z. Ur Rehman, "Modeling and Analysis of Series-Series and Series-Parallel Combined Topology for Wireless Power Transfer using Multiple Coupling Coefficients," IJCSNS Int. J. Comput. Sci. Netw. Secur., vol. 17, no. 11, pp. 114-123, 2017.

[19] A. Kurs, A. Karalis, R. Moffatt, J. D. Joannopoulos, P. Fisher, and M. Soljacic, "Wireless Power Transfer via Strongly Coupled Magnetic Resonances," Science, vol. 317, no. 5834, p. 83(4), 2007.

[20] D. W. Kim et al., "Effects and Properties of Contactless Power Transfer for HTS Receivers with Four-Separate Resonance Coils,” IEEE Trans. Appl. Supercond., vol. 23, no. 3, pp. 23-26, 2013.

[21] A. Christ, M. Douglas, J. Nadakuduti, and N. Kuster, "Assessing human exposure to electromagnetic fields from wireless power transmission systems," Proc. IEEE, vol. 101, no. 6, pp. 1482-1493, 2013.

[22] A. P. Sample, B. H. Waters, S. T. Wisdom, and J. R. Smith, "Enabling seamless wireless power delivery in dynamic environments," Proc. IEEE, vol. 101, no. 6, pp. 1343-1358, 2013.

[23] Q. Yuan, Q. Chen, L. Li, and K. Sawaya, "Numerical analysis on transmission efficiency of evanescent resonant coupling wireless power transfer system," IEEE Trans. Antennas Propag., vol. 58, no. 5, pp. 1751-1758, 2010.

[24] J. Kim et al., "Coil design and shielding methods for a magnetic resonant wireless power transfer system,” Proc. IEEE, vol. 101, no. 6, pp. 1332-1342, 2013.

[25] X. Mou and H. Sun, "Wireless power transfer: Survey and roadmap," IEEE Veh. Technol. Conf., vol. 2015, no. 646470, pp. 1-13, 2015.

[26] W. LOU LI GUANG XIE, YI SHI, Y. THOMAS HOU, “APPLICATIONS TO SENSOR NETWORKS WIRELESS POWER TRANSFER AND,” no. August, pp. 140-145, 2013.

[27] K. Miwa, H. Mori, N. Kikuma, H. Hirayama, and K. Sakakibara, "A consideration of efficiency improvement of transmitting coil array in wireless power transfer with magnetically coupled resonance," 2013 IEEE Wirel. Power Transf. WPT 2013, pp. 13-16, 2013.

[28] M. Rehman, P. Nallagownden, and Z. Baharudin, "Efficiency investigation of SS and SP compensation topologies for wireless power transfer," Int. J. Power Electron. Drive Syst., vol. 10, no. 4, pp. 2157-2164, 2019.

[29] X. Shi et al., "Effects of coil shapes on wireless power transfer via magnetic resonance coupling,” J. Electromagn. Waves Appl., vol. 28, no. 11, pp. 1316-1324, 2014.

[30] M. McDonough and B. Fahimi, "Comparison between circular and square coils for use in Wireless Power Transmission,” IET Conf. Publ., vol. 2014, no. 627 CP, pp. 2-3, 2014. 